\section{Bangladesh Medical Journal} Khulna

Vol. 43 No.1 \& 2 June \& December 2012

The Journal is published twice a year in the months of June and December

Editorial Board

Editor

Choudhury Habibur Rasul

Executive Editor

Syed Rezaul Karim

Managing Editor

Md Ashrafuzzaman

Assistant Editors

Kazi Hafizur Rahman

SM Kamal

Syed Mozammel Hossain

Sheikh Amir Hossain

Published by $\mathrm{CH}$ Rasul on behalf of Bangladesh Medical Association (Khulna). Printed by Uttaran Publications. 336, Sher-E Bangla Road, Khulna. All communications should be addressed to the Editor, Bangladesh Medical Journal (Khulna). Khulna Medical College, Khulna-9000, Bangladesh. <bangmedjk@ hotmail.com>

\section{EDITORIAL}

\section{VIOLENCE TOWARDS DOCTORS}

The level of violence in Health care facilities has been increasing at an alarming level throughout the country. These incidents decrease the self esteem of the doctors, jeopardize the doctor patient relationship and curtails humane attitude to the care of sick people. While most of the problem arises from patient's high expectation and unruly behaviour of the emotionally charged attendants, the flame is also fuelled by the dearth of trained manpower, sudden run out of life saving drugs and easy influx of antisocial elements in the hospital. Local authority tries to defuse the situation when it arises, by stringent control of attendants and presence of police in the hospital but temporary solace does not work long and the violence recurs. Professionals, patients and civil society look at the problem from different angles. Here are the few incidents, as reported in the news paper in the recent past.

National picture: In July 2011, an elderly patient with pyrexia of unknown origin occupied a bed in a cabin of Khulna Medical College Hospital $(\mathrm{KMCH})$ bypassing the normal procedure of admission. The caring department of Medicine was left uninformed and as such it took time to receive the patient. The influential attendants challenged the doctors for this delay and demanded special attention which was not possible with the existing workforce. At a point of brawl, the wife of the patient, a political activist slapped the clinical assistant which ignited a huge anarchy in the whole campus and the patient care in the entire hospital came to a halt for consecutive five days affecting the general people.

In May 2012, a deed writer was shot in the Khulna court area and he was rushed to nearby sadar hospital but the doctor inspite of declaring death referred him to $\mathrm{KMCH}$ although it was a spot dead case. Hundreds of political fellow accompanied the person when he was brought to $\mathrm{KMCH}$. Emergency doctors did not dare to declare death rather transported him to operation theatre where doctors tried to resuscitate the patient. Panic stricken doctors sought the help of law enforcing agencies but of no avail. By that time, as the attendants came to know that patient was actually dead; the crowds ransacked the operation theatre, paraded the whole hospital and assaulted the junior doctors nearby. The incident was followed by weeklong strikes by the interns who are the major workforces in a medical college hospital causing total disruption to patient management.

Apart from such major aggressions, minor problems like threatening, verbal abuse or harassment occur frequently, at least every week. These scenarios are similar in tertiary care hospitals and perhaps more so in secondary and primary care centre as seen in the daily news paper. Besides the government institutions, aggression is also a common feature in private hospital and practicing chambers, however the cause and nature of the aggression seems to be different.

The Government budget for health care and its management is intimately related with quality of patient care.1 The World Health Organization in their Global Health Statistics-2012 reported that Bangladesh spends only 21 USD per person per year on health care against the minimum necessary level of 44 USD. Among the SAARC countries this puts Bangladesh in a position below war-torn Afghanistan and only above Pakistan. In terms of percentage of total budget, allocation to health sector has gone down from $5.4 \%$ in the fiscal year 2011-12 to $4.9 \%$ in 2012-13. People now have to spend more from their own pocket which was $64 \%$ according to 2007 statistics.

Global situation: The violence toward doctors are not limited to Bangladesh alone, rather it prevails round the world. In China, the Ministry of Health reported that, in 2006 there 
were 9,831 major disturbances involving physical violence in Chinese health care facilities but by 2010 this number has increased to 17,243 . The problem in China was not only enormous in size but it is unique in character because of its fatal nature and is perpetrated by special vigilant group. $2 \mathrm{~A}$ recent large survey showed that $70 \%$ doctors won't want their own child to go into the medical profession. At the heart of the problem is the deteriorating doctor patient relationship due to mistrust and also sensational media reports about incidents of poor medical practice succeeded in fuelling the public mistrust. Other factors are, unrealistic expectations, the high cost of treatment, which is not only due to expensive new technologies and drugs, but also contributed by substantial incentives for doctors to profit from investigation and drug prescription leaving patient feel exploited.

The prevalence of occupational violence among health care workers in Norway, varies among professionals and health care settings but is found to be high in emergency department and among general practitioners. A study on the prevalence of occupational violence among health care workers of out patient setting defined four different type of aggression in the questionnaire for study- verbal abuse, threats, physical abuse and sexual harassment.3 The observations were :- (a) one in three doctors are exposed to physical abuse during their working hour. (b) Nurses experiences more verbal abuse than other occupational group. (c) The perceived main causes of violence are drug influence and mental illness.

There are limited Australian data describing patient aggression towards general practitioner and other staffs. A national survey in Australia revealed that 58\% General Physician (GP) had experienced verbal abuse and 18\% experienced property damage. Very few GPs had experienced physical abuse $(6 \%)$, stalking $(4 \%)$ and sexual harassment $(6 \%)$. GP with fewer year of practice were more likely to experience verbal abuse than those with more experience. Experienced GPs, through education and training may become better equipped to deal with verbal abuse and in defusing the situation.

Violence at work is a hidden phenomenon in most health care facilities in Italy and a study aimed at assessing the relationship between violence and psychosocial factors. One out of ten workers reported physical assault and one out of three was exposed to nonphysical violence in the previous year. Nurses and physicians were the most exposed occupational categories, whereas the psychiatric and emergency departments were the services at greatest risk of violence.

Across the globe, physicians in the emergency department are subject to violence by patients and visitors. This has been shown to have negative effect on patient care and physicians performances. A nationwide study in Pakistan identified that patient's lack of education, overcrowding in the emergency department and lack of coverage by security staff were the major areas that need attention to address the problem.4

The Health and Family Welfare department of Gujrat, India submitted a bill in the assembly on "Prevention of violence and damage or loss of property in medicare services". Through this bill, the government plans to make violence against doctors a cognizable and nonbailable offence, inviting stiff punishment. 5 The statement supporting this bill was: the role of medical professional is directly connected with human lives. Sometimes unexpected complications arise which may lead to death. At this time the relatives of the patient misunderstand the situation and commit the offence of assault and destruction of property. Antisocial elements also take advantage of the situation. The increase in incidence of such violence has resulted in unrest among medical persons, disruption of medical services and inconveniences to the general public.
Overcoming the problem: Doctors always become the easy target for the blame game accentuated by sensational media report. Physicians are popularly considered as a distinct group of people who are expected to serve the people even in the face of assault or humiliation. In fact, they possess all the virtues and vices of our community in our context. It would be an over-expectation to seek a radically different professional in one sector alone. On the other hand, optimum health care is the basic human right for all the citizens. Since a wide gap exists between expectation and reality, patients who feel aggrieved are forced to take matters in their own hands. This is attributed to the dearth in existing legal channels of suing for maltreatment and also to the inefficient and ineffective supervising institutions, perceived to favour medical professionals.

There are no short cut solutions to this multifaceted problem but several measures at different level can curb the present turmoil. a) Hospital authorities can regularly display their current status of doctors and drugs at entry point and strictly control the unnecessary attendants. b) Doctors, apart from tender and skilled clinical care can communicate with the anxious attendants regarding the condition of the patient and the possible treatment options. c) Bangladesh Medical Association, getting out of political affiliation, should divulge the real picture of health sector. It can advocate for improved doctor patient relationship having dialogue with other professionals and societies and also through mass media. d) Bangladesh Medical and Dental Council can set up a neutral body to deal with malpractice, medical disputes and obtaining compensation which must be efficient, fair and transparent both for doctors and patients. e) Ministry of Health should properly regulate the transfer and posting of doctors to ensure optimum manpower in the hospital. The referral system should be promoted to encourage the use of low cost primary care and prevent the huge flow of patients towards secondary and tertiary care. Introduction of zero profit policy for physicians on investigations and drugs and implementing health insurance system can reduce the out pocket personal cost for treatment.

Time is optimum now for our think tanks to work together to make a systematic change in the health care delivery system to avoid this untoward incidents thus ensuring round the clock quality service for the ailing persons.

CH Rasul FRCP Professor of Paediatrics Khulna Medical College \& Hospital

\section{References:}

1. Editorial. Health Care spending - Public health must be given priority. The Daily Star 28 August 2012

2. Hesketh $\mathrm{T}, \mathrm{Wu} \mathrm{D}$, Mao $\mathrm{L}$ et al. Violence against doctors in China. BMJ 2012; 345: e 5730

3. Joa TS, Morken T. Violence towards personnel in out of hours primary care-A cross sectional study. Scand J Primary Health Care 2012; 30: 55-60

4. Mirza MM, Amjad AI, Bhatti $\mathrm{ABH}$ et al. Violence and abuse faced by junior physicians in the emergency department from patients and their caretakers-a nationwide study from Pakistan. J Emer Med 2012; 42: 727-33

5. Express News Service. Government may table bill this week to protect doctors. The Indian Express 12 March 2012 